\title{
Editorial 25/3: Electronic Markets on ecosystems and tourism
}

\author{
Rainer Alt $^{1}$ • Hans-Dieter Zimmermann ${ }^{2}$
}

Published online: 14 August 2015

(C) Institute of Information Management, University of St. Gallen 2015

Dear readers of Electronic Markets,

This editorial was spurred by two observations. First, Electronic Markets (EM) enjoys a growing volume of submissions and now repeatedly receives manuscripts that are out of the journal's scope. Obviously, this requires an understanding on the topics that are within EM's scope. For this purpose, the following aims at clarifying this boundary. Second, the third issue of Electronic Markets includes a special issue on "Smart tourism". In fact, tourism was one of the industries that gave birth to electronic markets in the early 1960s and experienced an impressive development by transforming the entire airline industry. Thus, the editorial exploits the close link between the emergence of electronic markets and the history of computerized reservation systems (CRS) in tourism to clarify the scope of EM as well as to motivate the present special issue. When looking back, the phenomenon of electronic markets originated only in a small number of industries and was by no means as omnipresent as today. Among these industries were four sectors: agriculture, banking, retail and tourism.

- Agriculture used electronic markets, such as Telcot (Lindsey et al. 1990) in the U.S. or Calm (Lee and Clark 2003) in Australia to efficiently trade crops, plants, animals and the like. These systems featured key characteristics of electronic markets, such as organized trading, centralized

Rainer Alt

rainer.alt@uni-leipzig.de

Hans-Dieter Zimmermann

hansdieter.zimmermann@fhsg.ch

1 Information Systems Institute, University of Leipzig, Grimmaische Str. 12, 04109 Leipzig, Germany

2 FHS St. Gallen, University of Applied Sciences, Rosenbergstrasse 59, 9001 St. Gallen, Switzerland

sales negotiation, remote market access, description selling, and post-sale shipment (Henderson 1982).

- Banking relied on similar functionalities and saw the first computer-supported (e.g., Computer Assisted Trading System CATS at the Toronto Stock Exchange in 1977) and fully electronic exchanges (e.g., the Jersey Citybased National Stock Exchange NSX in 1980). Today, most transactions are conducted via these electronic platforms, which have become key elements of the banking value chain (Bons et al. 2012, 198).

- Retail has seen electronic markets in two domains. On the one hand customers were able to shop online as early as in the 1980s via videotext or phone using systems, such as Prodigy or Comp-U-Card (Malone et al. 1989, 167f), and on the other large consumer goods companies aimed at improving the efficiency of exchanging structured transaction data among their supply chain partner based on electronic data interchange (EDI) solutions.

- Tourism has probably seen the most impressive evolution of electronic markets, which have become known as CRS or global distribution systems (GDS). The exciting summary of Copeland and McKenney (1988) shows how internal inventory control systems were developed by airlines to electronic markets, which also included competitors.

Before focusing on the domain of tourism, the historical perspective also sheds light on the fact that electronic markets were part of the larger field referred to as interorganizational systems (IOS). It not only comprised electronic markets, but also bilateral and multilateral (so-called clearing centers) EDI linkages among businesses as well as electronic ordering systems. However, a brief analysis of the term "electronic markets" suggests that a broader dissemination was closely linked to the diffusion of the Internet. Beyond the scholarly 
community, the term was little known in the 1980s and the early 1990s. According to Factiva, it was only in 1994, that the number of articles published in business publications exceeded 100 articles for the first time - for 1997, Factiva reports more than 500 respective articles. From then until 2014 , the number of articles ranged roughly between 600 and 800 articles p.a. without any clear trend in neither direction. This underlines the fact that with the advent of "electronic business" (e-Business) and "electronic commerce" (e-Commerce) in the mid-1990s, electronic markets also thrived, however, with some exaggerated expectations as well (Alt and Klein 2011). Unlike the IOS path, the Internet path describes the birth of a reliable means of asynchronous communication in the public sector, which became institutionalized (e.g., ICANN, IETF, W3C) and commercialized during the 1990s. Many businesses established their first corporate websites and subsequently the standardized Internet protocols were also discovered for business processes, in particular for information and transaction purposes. Portals and integration platforms emerged subsequently as well as mobile and social technologies. Both were important technological enablers for many new use cases or application scenarios.

In addition to the IOS and the Internet path, a third path may be observed, which is critical for the seamless automation of processes among businesses. Starting in the 1970s as well, standard software packages for enterprise operations emerged, which were labeled enterprise resource planning (ERP) or enterprise systems (Davenport 1998). These systems strived not only to support independent business functions (e.g., accounting), but to integrate data and processes across functional boundaries within a firm. When implementing these systems, businesses often redesigned their structural as well as their process organization (business process redesign, BPR). Thus, the introduction of ERP software packages not only brought agreed-on internal data definitions, but also standardized interfaces to external parties, such as suppliers, customers and service providers. Following developments in the ERP world were strongly linked with the commercialization of the Internet and "classical IOS" topics, such as electronic commerce, customer relationship and supply chain management (CRM, SCM). Additional modules were developed by companies, such as i2 Technologies and Manugistics (now both part of JDA), Ariba (now SAP) and Commerce One (now Perfect Commerce). In a next step, modularization and virtualization led to more standardized ERP services that were available via software-as-a-service or cloud technologies. As stated by Venkatraman (1994) internal integration formed the basis for redesigning processes (BPR) within businesses, which in turn was the prerequisite for redesigning activities within business networks and eventually transforming entire businesses and industries.

The transformational power is also visible in the convergence of the three development paths. Although these paths have different origins, they have started to converge, at least since the mid-1990s, and are in the process of shaping an electronic (or digital) inter-organizational information infrastructure or digital ecosystem (Fig. 1). Today, the Internet is not only the standard technology for websites, but also for ordering and ERP systems. ERP systems are not only limited to internal processes, but also handle processes with external partners (e.g., supply chain planning within a business network). Ultimately, this extends the mutual relationship between business process redesign (BPR) and ERP as intraorganizational information infrastructures into the inter-organizational realm. These infrastructures may enable new networked processes, which vice versa generate demand for new technological solutions. Consequently, many perspectives and facets have been added to the original field of "electronic markets" over time.

A retrospective on relevant topics published in EM mirrors the convergence of the three development paths mentioned above. For example, an analysis of over 800 publications published at the Bled eConference revealed that a first phase of research, called "1988-1995-EDI", addressed topics around EDI and IOS, while a second phase was labeled "19962004-eCommerce" and focused on the integration with supply chain and, later, with (e)marketing activities as well. The third phase "since 2005-eInteraction" saw the inclusion of consumers and the use of mobile as well as social media technologies (Clarke and Pucihar 2013). A more recent review has suggested six stages in the evolution of relevant topics in EM (Alt and Zimmermann 2014, 162). Starting from the 1970s the topics were EDI and IOS, E-Commerce and EBusiness, digital value chains and ecosystems. Clearly, new technological developments such as mobile communication, cloud computing, social media and many more added additional aspects to the E-Business debate during the last 25 years. While this enlarged the scope of EM, it emphasizes that submissions to EM need to address some problem associated with the IT-based networking among the participants in a value chain or an ecosystem, which also explicitly includes customers or consumers.

Ecosystems are a prominent example of the power of convergence. The origins of the term reach back to the 1930s and referred to natural systems comprising living organisms as well as non-living elements interacting as a system. Economic ecosystems (Moore 1996) and digital ecosystems have only been discussed since the mid-1990s (Nachira et al. 2007). The former have been defined as "an economic community supported by a foundation of interacting organisations and individuals [...]. This economic community produces goods and services of value to customers, who are themselves members of the ecosystems. The member organisations also include suppliers, lead producers, competitors, and other stakeholders" (Moore 1996, p. 26). In addition, the latter term 


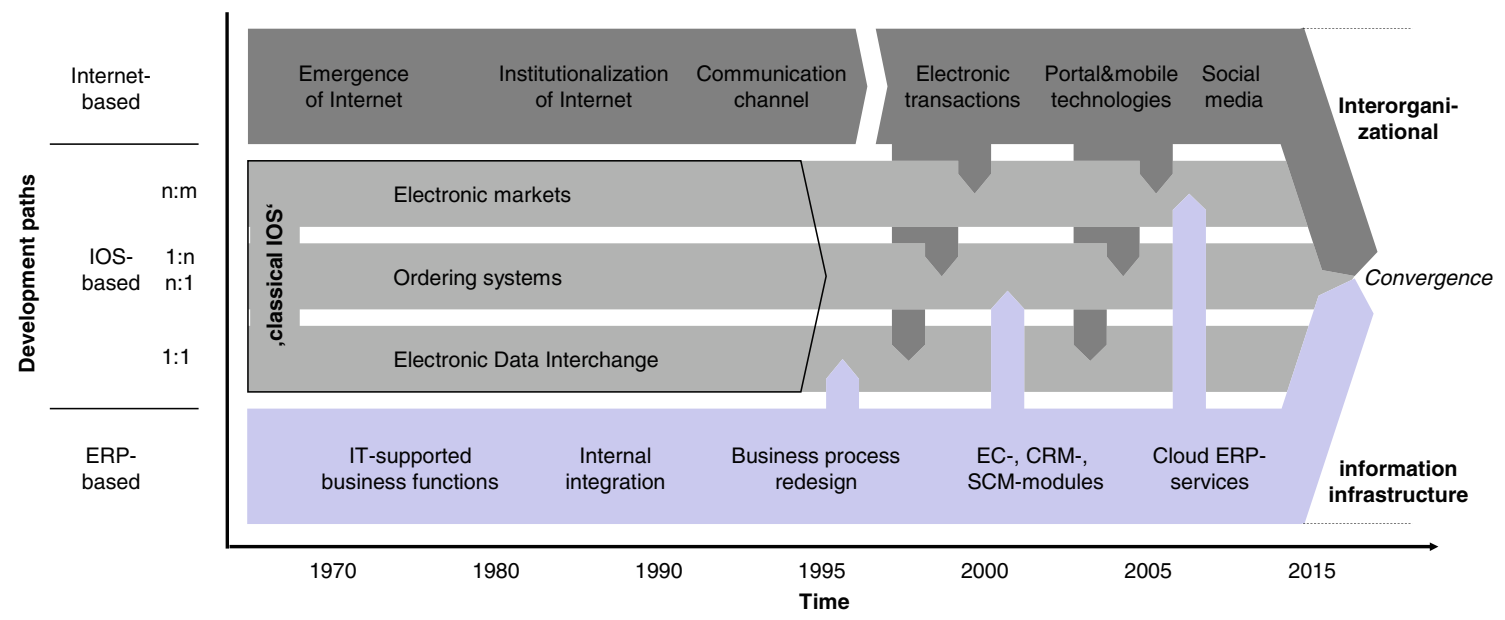

Fig. 1 Emergence of inter-organizational information infrastructure (Alt 2008, 41)

posits that "[d]igital ecosystems transcend the traditional, rigorously defined, collaborative environments from centralized, distributed or hybrid models into an open, flexible, domain cluster, demand-driven, interactive environment" (Boley and Chang 2007, p. 2933). Thus, ecosystems may be understood as distributed business networks, which consist of adaptive and self-organizing communities of providers and users and which rely on IT to achieve their objectives. In digital ecosystems, companies become a destination to solve a customer's life or business need with products and services from their company, from complementors and from competitors as well. Recent research has suggested that businesses thinking more broadly about their position in a digital ecosystem are more successful than others (Weill and Woerner 2015).

Well-known representatives of current digital ecosystems that generate value and lock-in effects with customers at the same time are Amazon, Apple, or Google. Currently, these ecosystems are extending their services into other domains and the question remains how traditional players will achieve to transform their business model and offering in the ecosystem direction. An example that has been discussed is the value chain in banking (Bons et al. 2012). Compared to manufacturing industries, many banks maintained a high degree of vertical integration until the late 1990s. Factors, such as globalized markets, regulation requirements, competition from nonbanks and the increasing diffusion of IT in all areas of the value chain are contributing to a transformation of the entire industry towards more networked models (Alt and Puschmann 2012). However, the "new market players from the non-bank sector [...] have an almost perfect understanding of the language of the internet" (Dapp 2015, p. 1) and proactively establishing a platform-based, digital banking ecosystem as a "walled garden" is an opportunity to prevent an analogous fate as the once leading maker of mobile phones Nokia experienced with the emergence of smartphone-based ecosystems. These ecosystems also provide a view on the role of electronic markets:

- First, digital ecosystems comprise electronic marketplaces as central elements with examples, such as the Apple AppStore, the Google Play Store or closed app stores within enterprises or business networks (Basole and Karla 2011; Adner 2012). This follows the early ecosystem definitions mentioned above.

- Second, electronic markets may be considered as ecosystems themselves. They comprise different services necessary to establish an electronic marketplace beyond the pure market coordination mechanism, e.g., electronic product catalogues, negotiation and trust as well as different fulfillment services (Alt and Klein 2011, p. 44f). In this vein, the electronic platform is "the network of innovation to produce complements that make a platform more valuable" (Gawer and Cusumano 2002).

On the other hand, a review of past research on the topics mentioned above shows the different faces of electronic markets. To understand the various effects, electronic markets were analyzed from various perspectives. For example, Henderson (1982) applies a more system-oriented lens than Malone et al. (1987) who focus on corresponding governance mechanisms. Both are included in the overview on possible perspectives and drivers for electronic markets by Alt and Klein (2011, p. 43). One dimension perceives electronic markets as an economic environment, a mode of governance or a business model. In another dimension, the main drivers "technology push", "market dynamics" and "institutional design" are distinguished. This underlines EM's mission to cover "diverse aspects of networked business and [...] research from a technological, organizational, societal, and/or political perspective" (EM 2015). Although, EM is a methodologically pluralistic journal, authors should pay ample attention on telling an innovative story. Empirical soundness is an 
important, but not sufficient requirement. The contributions to the field need to be apparent and all authors should be motivated to present surprising findings that help further elucidate the nature of future electronic ecosystems.

For instance, Bakos (1998) not only provides an in-depth discussion on the terms eMarketplace and electronic markets, but also on the possible functionalities by illustrating them with multiple cases, including the airline industry. Another example is Malone et al. (1987), who also used the airline industry as an example in their argumentation towards the well-known "electronic markets hypothesis". Based on a transaction cost rationale they forecasted a "move-to-themarket", i.e., an IT-driven change of governance structures and a diffusion of electronic markets in many industries where asset specificity and the complexity of product description were limited. This seminal paper has become the most cited article in the information systems field with close to 900 citations in the ISI Web of Science index and more than 3'800 citations according to Google Scholar (as of mid-June 2015). It is the main starting point for the scholarly discourse on emerging IT-supported and enabled business structures and processes. By triggering scholarly discussions until today it is also an impressive example that scientific publications may not only address relevant issues and achieve long-term impact. It shows the power of prospective research that aims at forecasting future developments instead of pursuing retrospective research that primarily aims at understanding the past (Alt and Österle 2014).
This leads us to the present issue of EM, which offers fresh insights into the world of "smart tourism". As mentioned above, one of the first IOS that may be considered as electronic markets were the CRS developed by major players in the airline industry, such as American Airlines, United, Lufthansa and others. In the beginning CRS were primarily used as inventory-control systems by airlines with first solutions (e.g., SABRE) already emerging in the 1950s and 1960s (Kärcher 1996). Later, CRSs developed to facilitate business transactions and bookings related to air travel. They were extended for the use of travel agencies, hotels, and other tourism and hospitality businesses to manage their inventory and to allow direct access through terminals to check for availability, make reservations and issue tickets. While CRSs had their main focus on inventory management and direct reservations, they developed into much more comprehensive global distribution systems (GDS) since the mid-1980s offering a wide range of tourism products and providing the backbone mechanism for communication between the key actors in the tourism industry. Since the early 1990s, GDSs became true unbiased electronic markets, offering information and reservation capabilities for the entire range of travel products, including accommodation, car rentals, schedules for non-air transportation etc. (Buhalis 2004). Multiple articles in EM have repeatedly covered related topics (see Table 1). However, the convergence is also prevalent in this industry and now illustrates increasing competition between CRS and other distribution channels. Players, such as HRS, Booking.com and

Table 1 Articles on (electronic) tourism in EM

\begin{tabular}{|c|c|c|}
\hline Issue & Article & Authors \\
\hline $24 / 1$ & $\begin{array}{l}\text { A Service Innovation Evaluation Framework for Tourism E-Commerce in China Based on } \\
\text { BP Neural Network }\end{array}$ & Lifang Peng \& Lingling Lai \\
\hline $19 / 1$ & $\begin{array}{l}\text { Designing for Reintermediation in the Brick-and-Mortar World: Towards the Travel Agency } \\
\text { of the Future }\end{array}$ & Jasminko Novak \& Gerhard Schwabe \\
\hline $17 / 2$ & Tourism and Travel Electronic Commerce in China & Yaobin Lu, Zhaohua Deng \& Bin Wang \\
\hline $13 / 1$ & Emerging Pricing Strategies on the Web: Lessons from the Airline Industry & Stefan Klein \& Claudia Loebbecke \\
\hline $10 / 2$ & Destination Maui? An Exploratory Assessment of the Efficacy of Self-Booking in Travel & Bill Anckar \& Pirkko Walden \\
\hline $9 / 4$ & $\begin{array}{l}\text { Electronic Markets in Transport: Comparing the Globalization of Air and Rail Computerized } \\
\text { Reservation Systems }\end{array}$ & Nathalie N. Mitev \\
\hline $9 / 4$ & ICT and the Changing Landscape of Global Tourism Distribution & Hannes Werthner \& Stefan Klein \\
\hline $8 / 2$ & Distribution of Danish Tourism Products in Europe-Status, Trends and Challenges & Carl H. Marcussen \\
\hline $7 / 2$ & Gulliver - Distributing Irish Tourism Electronically & Peter O’Connor \& John Rafferty \\
\hline $7 / 1$ & The Main National Travel And Tourism Distribution Systems in Britain And Germany & Karsten Kärcher \\
\hline $6 / 2$ & The Four Global Distribution Systems in the Travel and Tourism Industry & Karsten Kärcher \\
\hline $6 / 1$ & Enhancing the Competitiveness of Small and Medium-sized Tourism Enterprises & Dimitrios Buhalis \\
\hline $6 / 1$ & Electronic Markets and Tourism & Karsten Kärcher \\
\hline $6 / 1$ & User-driven Applications of Advanced Networks for Electronic Marketing of Tourism Products & Paul F. Byerley \& Johannes Ewers \\
\hline $6 / 1$ & TIM and SAM: Use of Technology to Create New Business Relationships for Tourism & Stephen Connell \\
\hline $6 / 1$ & Info Austria / Eurostart Austria: The All-Austrian Tourism Information and Reservation System & Leo Bauernberger \& Susanne Reiger \\
\hline $5 / 2$ & Electronic Markets in Tourism - Constraints and Opportunities & Gilbert H. Archdale \\
\hline
\end{tabular}


other so-called Online Travel Agencies (OTA) as well as proprietary airline systems (e.g., Ryanair) have made inroads into the market. Recently growing booking fees (Taylor 2015) have also contributed to the "battle of channels" in the tourism industry.

CRS have become a contested market segment and developed into a business on their own. They show that electronic markets are not only transaction platforms efficiently facilitating transaction processing but have developed into ecosystems comprising different players based on IOS. The present special issue of EM adds the word "smart" to the discussion and also sheds light on the ongoing "big data" hype. We thank the team of guest editors for organizing this special issue. Ulrike Gretzel (University of Queensland), Chulmo Koo (Kyung Hee University), Marianna Sigala (University of South Australia) and Zheng Xiang (Virginia Polytechnic Institute and State University) managed to attract a comprehensive issue for this interesting topic. It includes four articles as well as a position paper, which describes the foundations and developments of smart tourism (Gretzel et al. 2015b). The position paper is freely available on the Springerlink site. The guest editors will also introduce the papers of this special issue in their preface (Gretzel et al. 2015a).

Finally, we are indebted to the EM community, which convened at the latest Editorial Board Meeting held at ECIS 2015 in Münster, Germany, for their feedback. They also elected Ali Sunyaev (University of Cologne, Germany) and Pedro Soto-Acosta (University of Murcia, Spain) as new members of the editorial board. We welcome these esteemed colleagues, who were already involved in reviews and special issues to EM! We are also sure that this strong commitment of all stakeholders - authors, readers, reviewers, board members and editors - contributed to the latest increase of EM's impact factor (from 0.769 for 2013 to 0.935 for 2014) as well. Thank you and we hope that you keep supporting EM!

Best regards from Leipzig and St. Gallen,

Rainer Alt, Hans-Dieter Zimmermann

\section{References}

Adner, R. (2012). Amazon vs. Apple: competing ecosystem strategies. Harvard Business Review. Retrieved from https://hbr.org/2012/03/ amazon-vs-apple-competing-ecos

Alt, R. (2008). Überbetriebliches Prozessmanagement. Berlin: Logos.

Alt, R., \& Klein, S. (2011). Twenty years of electronic markets research looking backwards towards the future. Electronic Markets, 21(1), 41-51. doi:10.1007/s12525-011-0057-z.

Alt, R., \& Österle, H. (2014). Editorial 24/1: Electronic Markets and practice-orientation. Electronic Markets, 24(3), 1-3. doi:10.1007/ s12525-014-0152-z.

Alt, R., \& Puschmann, T. (2012). The rise of customer-oriented banking electronic markets Are paving the Way for change in the financial industry. Electronic Markets, 22(4), 203-215. doi:10.1007/s12525012-0106-2.
Alt, R., \& Zimmermann, H.-D. (2014). Editorial 24/3: Electronic Markets and general research. Electronic Markets, 24(3), 161-164. doi:10. 1007/s12525-014-0163-9.

Bakos, Y. (1998). The emerging role of electronic marketplaces on the internet. Communications of the ACM, 41(8), 35-42. doi:10.1145/ 280324.280330.

Basole, R. C., \& Karla, J. (2011). On the evolution of mobile platform ecosystem structure and strategy. Business and Information Systems Engineering, 3(5), 313-322. doi:10. 1007/s12599-011-0174-4.

Boley, H., \& Chang, E. (2007). Digital ecosystems: principles and semantics. In digital EcoSystems and technologies conference, 2007. DEST'07. Inaugural IEEE-IES (pp. 398-403). Cairns, Australia: IEEE Industrial Electronics Society. doi:10.1109/DEST.2007. 372005.

Bons, R. W. H., Alt, R., Lee, H. G., \& Weber, B. (2012). Banking in the internet and mobile Era. Electronic Markets, 22(4), 197-202. doi: 10.1007/s12525-012-0110-6.

Buhalis, D. (2004). EAirlines: strategic and tactical Use of ICTs in the airline industry. Information and Management, 41(7), 805-825. doi: 10.1016/j.im.2003.08.015.

Clarke, R., \& Pucihar, A. (2013). Electronic interaction research 1988 2012 through the lens of the bled eConference. Electronic Markets, 23(4), 271-283. doi:10.1007/s12525-013-0144-4.

Copeland, D. G., \& McKenney, J. L. (1988). Airline reservations systems: lessons from history. MIS Quarterly, 12(3), 353-370. doi:10. 2307/249202.

Dapp, T. F. (2015). Fintech reloaded - traditional banks as digital ecosystems. Deutsche Bank, Frankfurt: DB Research.

Davenport, T. H. (1998). Putting the enterprise into the enterprise system. Harvard Business Review, 76(4), 121-131.

EM (2015). Electronic markets' scope. http://www.electronicmarkets.org/ about-em/scope/. Accessed on July 20, 2015.

Gawer, A., \& Cusumano, M. A. (2002). Platform leadership: How intel, microsoft, and Cisco drive industry innovation. Boston: Harvard Business School Press.

Gretzel, U., Koo, C., Sigala, M., Xiang, Z. (2015a). Special Issue on smart tourism: convergence of information technologies, experiences, and theories. Electronic Markets, 25(3). doi:10.1007/ s12525-015-0194-X.

Gretzel, U., Sigala, M., Xiang, Z., Koo, C. (2015b). Smart tourism: foundations and developments. Electronic Markets, 25(3). doi:10.1007/ s12525-015-0196-8.

Henderson, D. R. (1982). Electronic markets for agricultural commodities: potentials and pitfalls (No. WP-62). Retrieved from http:// econpapers.repec.org/RePEc:ags:uwfswp:202987.

Kärcher, K. (1996). The four global distribution systems in the travel and tourism industry. Electronic Markets, 6(2), 20-24. Retrieved from http:/www.electronicmarkets.org/fileadmin/ user_upload/doc/Issues/Volume_06/Issue_02/The_Four Global Distribution.pdf.

Lee, H. G., \& Clark, T. H. (2003). Strategies in response to the potential of electronic commerce: market process reengineering through electronic market systems: opportunities and challenges. In Galliers, R. D. \& Leidner, D. E. (Eds.), Strategic information management, 3rd edition (pp. 347-375). Burlington, MA: Butterworth-Heinemann.

Lindsey, D., Cheney, P. H., Kasper, G. M., \& Ives, B. (1990). TELCOT: an application of information technology for competitive advantage in the cotton industry. MIS Quarterly, 14(4), 347-357. doi:10.2307/ 249781.

Malone, T. W., Yates, J., \& Benjamin, R. I. (1987). Electronic markets and electronic hierarchies. Communications of the ACM, 30(6), 484-497. doi: $10.1145 / 214762.214766$.

Malone, T. W., Yates, J., \& Benjamin, R. I. (1989). The logic of electronic markets. Harvard Business Review, 67(3), 166-170. 
Moore, J. F. (1996). The death of competition - leadership and strategy in the Age of business ecosystems. New York: HarperBusiness.

Nachira, F., Nicolai, A., Dini, P., Louarn, M. L., Leon, L. R. (Eds.). (2007). Digital Business Ecosystems. Luxemburg: European Commission. Retrieved from http://www.digital-ecosystems.org/ book/de-book2007.html.

Taylor, I. (2015). Lufthansa imposes $€ 16$ fee on GDS bookings. travelweekly, June 3. Retrieved from http://www.travelweekly.co.
uk/Articles/2015/06/03/54406/lufthansa-imposes-16-fee-on-gdsbookings.html.

Venkatraman, N. (1994). IT-enabled business transformation: from automation to business scope redefinition. Sloan Management Review, 35(2), 73-87.

Weill, P., Woerner, S. L. (2015). Thriving in an increasingly digital ecosystem. MIT Sloan Management Review. Retrieved from http://sloanreview.mit. edu/article/thriving-in-an-increasingly-digital-ecosystem/. 